\title{
Extended pelvic resections for the treatment of locally advanced and recurrent anal canal and colorectal cancer: technical aspects and morbimortality predictors aftet $\mathbf{2 4}$ consecutive cases
}

\section{Ressecções pélvicas alargadas no tratamento do câncer colorretal e de canal anal localmente avançado ou recidivado: análise dos aspectos técnicos e fatores de morbimortalidade em 24 casos consecutivos}

José Wilson Benevides de Mesquita Neto'; Davy Bruno Machado'; Dárcio Jânio Macedo; Diego Fonseca Cordeiro3; Eurivaldo Valente de Brito3; Marcelo leite Vieira Costa ${ }^{4}$

\begin{abstract}
A B S T R A C T
Objective: to evaluate the profile of morbidity and mortality and its predictors related to extensive pelvic resections, including pelvic exenteration, to optimize the selection of patients and achieve better surgical results. Methods: we performed 24 major resections for anorectal pelvic malignancy from 2008 to 2015 in the Instituto do Câncer do Ceará. The factors analyzed included age, weight loss, resected organs, total versus posterior exenteration, angiolymphatic and perineural invasion, lymph node metastasis and overall and disease-free survival. Results: the median age was 57 years and the mean follow-up was ten months. Overall morbidity was $45.8 \%$, with five $(20.8 \%)$ serious complications. There were no deaths in the first 30 postoperative days. The median overall survival was 39.5 months, and disease-free survival, 30.7 months. Concomitant resection of the bladder was an isolated prognostic factor for higher risk of complications ( $87.5 \%$ vs. $26.7 \%, p=0.009$ ). Angiolymphatic invasion and lymph node metastasis did not reach significance with respect to disease-free survival. Conclusion: treatment of advanced anorectal tumors is challenging, often requiring combined resections, such as cystectomy and sacrectomy, and complex reconstructions. The magnitude of the operation still carries a high morbidity rate, but is a procedure considered safe and feasible, with a low mortality and adequate locoregional tumor control when performed in referral centers.
\end{abstract}

Keywords: Neoplasms. Rectal Neoplasms. Recurrence. Anal Canal. Pelvic Exenteration.

\section{INTRODUCTION}

Cigr olorectal cancer (CRC) is the most common malignancy of the digestive tract1. For epidemiological purposes, included in this group are also the malignant anal canal neoplasms (ACN).

In recent decades, there has been great progress in treating these malignancies, with the incorporation of multimodal therapy with chemotherapy and radiotherapy. In ACN, for example, the exclusive chemoradiation therapy is curative in up to $85 \%$ of cases, reserving surgery only for recurrence or persistent disease2. For CRC, although radiotherapy and chemotherapy do not have a exclusive curative role, they have shown benefit in the context of adjuvant or neoadjuvant therapy. Surgery remains as the only well-established treatment with curative potential, also representing a rescue option in recurrence cases3. Extensive pelvic resections rise as the only possibility of cure for patients with extensive locoregional recurrence despite conservative surgical treatment, and in cases with invasion of adjacent organs. They comprise genito-urinary tract resections (pelvic exenteration - PE) and composite resections, including bone segments or soft tissue4.

PE was first described by Brunschwig 5, in 1948 , being set as a high mortality surgery that consisted of removing all the pelvic organs, including the urinary system (bladder, distal urethra and prostate gland), the reproductive one (uterus, vagina) and rectosigmoid. Combined resections are characterized by the removal of organs or segments that do not include the ones mentioned above, such as the sacrum or coccyx, perineal skin, vulva etc.

\footnotetext{
1 - Departamento de Oncologia Digestiva. Instituto do Câncer do Ceará - Hospital Haroldo Juaçaba (HHJ-ICC). Fortaleza/CE, Brasil; 2 - Programa de Cancerologia Cirúrgica. Instituto do Câncer do Ceará - Hospital Haroldo Juaçaba (HHJ-ICC). Fortaleza/CE, Brasil; 3 - Escola Cearense de Oncologia. Instituto do Câncer do Ceará - Hospital Haroldo Juaçaba (HHJ-ICC). Fortaleza/CE, Brasil; 4 - Departamento de Cirurgia da Faculdade de Medicina da Universidade Federal do Ceará. Fortaleza/CE, Brasil.
} 
Table 1. Degree of complications according to the Dindo-Clavien scale

\begin{tabular}{|c|c|}
\hline Grade & Definition \\
\hline 0 & No complicator observed \\
\hline 1 & $\begin{array}{l}\text { Any deviation from the normal course without the need for pharmacological treatment or surgical, } \\
\text { endoscopic and radiologic interventions } \\
\text { Allowed therapeutic regimens are: drugs as antiemetics, antipyretics, analgetics, diuretics, electrolytes and } \\
\text { physiotherapy. This grade also includes wound infections opened at the bedside }\end{array}$ \\
\hline 2 & $\begin{array}{l}\text { Requiring pharmacological treatment with drugs other than such allowed for grade I complications. Blood } \\
\text { transfusions* and total parenteral nutrition are also included }\end{array}$ \\
\hline $3 a$ & Requiring surgical, endoscopic or radiological intervention not under general anesthesia \\
\hline $3 b$ & Requiring surgical, endoscopic or radiological intervention under general anesthesial \\
\hline 4 & Death-threatening complication that needs intensive care support, with dysfunction of one organ \\
\hline 5 & Death \\
\hline
\end{tabular}

* Neste trabalho, assim várias publicações mais recentes, modificou-se a classificação de Dindo-Clavien e hemotransfusão não foi considerada como complicação pós-operatória.

Today, pelvic resections are carried out safely and with low mortality in many centers around the world, while their morbidity persists, ranging around $60 \%$ in cases requiring bladder resection 4 .

The objective of this study is to evaluate clinical and epidemiological aspects, technical details and prognostic factors of complications related to such large resections, to optimize treatment and selection of candidates for these procedures, providing a greater chance of cure, less morbidity and better quality of life.

\section{METHODS}

We conducted a retrospective cohort study including all cases of enlarged pelvic resections of the Departamento de Oncologia Digestiva in the period from January 1st, 2008 to October 1st, 2015, at the Hospital Haroldo Juaçaba of the Instituto do Câncer do Ceará (HHJ-ICC). We included only patients matching the following eligibility criteria: a) surgery conducted by HHJ-ICC staff; b) rectosigmoidectomy with or without abdominoperineal amputation of the rectum, associated with one or more procedures required due to direct tumor invasion: hysterectomy, cystectomy, prostatectomy, sacrectomy, coccyx resection vulvectomy, colpectomy, extensive perineal resection of soft tissue requiring flap rotation; and c) primary site set to rectosigmoid or anal canal. All data were recorded in a specific protocol form.

The variables analyzed were: gender, age, diagnosis, symptoms and weight loss, body mass index (BMI), type of surgery, blood transfusion, admission to the intensive care unit, method of reconstruction of the gastrointestinal and urinary tract, mortality and morbidity, lymph node involvement, angiolymphatic and perineural invasion, overall survival (OS) and disease-free survival (DFS).

The type of resection has been classified as: a) classic total pelvic exenteration (TPE): removal of the rectosigmoid with the bladder (in man) and the uterus (in female); b) classic posterior pelvic exenteration (PPE): resection of the rectosigmoid and uterus in women; c) other extended resections (OER): other resections not classified in the previous classifications.

For analysis of morbidity, when the OER cases also included pelvic exenteration, we classified them as TPE or PPE plus the specification of the additional segment removed.

Operative mortality was defined as death within 30 days of surgery. Morbidity was rated according to the scale of Dindo-Clavien6, with modifications, taking into account the clinical outcome and the therapy employed for resolution (Table 1).

For grouping of categorical variables, the complications were defined as minor (Clavien grades 
1 or 2) and major (grades 3 or 4). We also split the category of major complications, separating them into non-severe (grade 3a) and severe (grades $3 b$ and 4). The inclusion of this subdivision is justified by the fact that there is an important practical difference in the management of complications grades $3 \mathrm{a}$ and $3 \mathrm{~b}$.

We present results as median, mean and standard deviation, absolute and relative frequency. Categorical variables were compared within groups using the chi-square and Fisher's exact tests, as appropriate. All statistical analysis was performed with SPSS Statistics $₫$ software 19. We considered a $p$ value of 0.05 as significant. We also used a spreadsheet software to assist in the tabulation of data and preparation of graphics.

The work was approved by the Ethics in Research Committee of the Hospital Haroldo Juaçaba-Instituto do Câncer do Ceará, Opinion No 006/2011 of 24/02/2011.

\section{RESULTS}

From January 1st, 2008 to October 1st, 2015 we held 24 extended pelvic resections in the Departamento de Oncologia Digestiva of the Instituto do Câncer do Ceará for the treatment of colon, rectum and anus cancer exclusively. The same surgical team performed all procedures.

Twenty patients $(83.3 \%)$ were female and four $(16.7 \%)$ were male. The age ranged from 35 to 74 years, with a median of 57 years. In 14 (70\%) cases we could obtain anthropometric data of the first hospitalization. The weight ranged from 37 to $65.5 \mathrm{~kg}$ (mean 51.7 and median 51.5), and the BMI, 16.23 to $31.57 \mathrm{~kg} / \mathrm{m} 2$ (average 23.44 and median 22.5) (Table 2).

All patients were symptomatic, the period of time between onset of symptoms and the first visit ranging from two to 120 months. The most common symptom was rectal bleeding, reported by 19 (79.2\%) patients, followed by pain in 17 (70.8\%) and weight loss in 14 (58.3\%).

In relation to multimodal therapy, all 24 $(100 \%)$ patients underwent radiotherapy or chemotherapy during the course of treatment. Eighteen
Table 2. Characteristics of the 24 patients who underwent pelvic exenteration.

\begin{tabular}{|c|c|}
\hline Total of patients $(n)$ & $24(100 \%)$ \\
\hline \multicolumn{2}{|l|}{ Gender } \\
\hline Female & $20(83,3 \%)$ \\
\hline Male & $4(16,7 \%)$ \\
\hline Age (median) & $57(35-74)$ \\
\hline $\mathrm{BMI}(\mathrm{n})$ & 14 \\
\hline Malnourished $(<18,5$ kg/m2) & $2(14,2 \%)$ \\
\hline Eutrophic $(18,5-24,9)$ & $7(50 \%)$ \\
\hline Overweight $(25-29,9)$ & $3(21,4 \%)$ \\
\hline Obesity $(>29,9)$ & $1(7,1 \%)$ \\
\hline \multicolumn{2}{|l|}{ Tumor site } \\
\hline Superior rectum & $1(4,2 \%)$ \\
\hline Middle rectum & $7(29,2 \%)$ \\
\hline Lower rectum & $8(33,3 \%)$ \\
\hline Sigmoid & $1(4,2 \%)$ \\
\hline Multicentric (colon e rectum) & $1(4,2 \%)$ \\
\hline Anal canal & $6(25 \%)$ \\
\hline \multicolumn{2}{|l|}{ Symptomatology } \\
\hline Time of symptoms & $6(2-120)$ \\
\hline Abdomino-pelvic pain & $17(70,8 \%)$ \\
\hline Visible tumor & $2(8,3 \%)$ \\
\hline Asthenia & $3(12,5 \%)$ \\
\hline Weight loss (>10\% in 6 months) & $14(58,3 \%)$ \\
\hline Hematochezia & $19(79,2 \%)$ \\
\hline Rectovaginal fistula & $3(12,5 \%)$ \\
\hline Rectovesical fistula & $1(4,2 \%)$ \\
\hline \multicolumn{2}{|l|}{ Complementary treatment } \\
\hline Neoadjuvant radiochemotherapy & $\begin{array}{l}18(75 \%) \\
3,55(1,05-\end{array}$ \\
\hline Preoperatıvely CEA $(n=14)$ & $122,7)$ \\
\hline \multicolumn{2}{|l|}{ Complications } \\
\hline Respiratory complications & $4(16,7 \%)$ \\
\hline Surgical site infection & $6(25 \%)$ \\
\hline Abdominal wall dehiscence & $4(16,7 \%)$ \\
\hline Acute renal failure & $2(8,3 \%)$ \\
\hline Prolonged ileum & $1(4,2 \%)$ \\
\hline Urinary retention & $3(12,5 \%)$ \\
\hline $\begin{array}{l}\text { Fistula of the urinary } \\
\text { reconstruction }\end{array}$ & $1(4,2 \%)$ \\
\hline Colostomy necrosis & $1(4,2 \%)$ \\
\hline
\end{tabular}

Source: HHJ-ICC (2008-2012). 
(75\%) patients underwent concomitant chemoradiotherapy before surgery, complementing systemic therapy postoperatively. Six $(25 \%)$ underwent only adjuvant chemotherapy. The regimens were 5-fluorouracil (5-FU) with leucovorin (LV), with or without oxaliplatin, 5-FU with cisplatin (CDDP) and capecitabine alone.

Regarding the extent of resection, each case is detailed in Table 3. Additional organs removed in extended resections were: uterus and appendages, vagina, prostate and bladder, sacrum in the S3 level and below, coccyx, perineum and buttocks skin, vulva, right colon and kidney. The most commonly used soft tissue reconstruction method was the vertical myocutaneous flap of the rectus abdominis (VRAM) in seven cases, with construction of neovagina in two patients.

As for the reconstruction of the gastrointestinal tract, the preservation of the anus sphincter with a primary anastomosis was possible in nine (37.5\%) cases. We performed a double-barreled wet colostomy (DBWC) in five (20.8\%) patients and isolated terminal colostomy in ten (41.6\%).
Seven $(29.1 \%)$ patients received intraoperative blood transfusion, with a number of packed red blood cells that ranged from two to four.

The overall morbidity was $45.8 \%$, with 17 postoperative complications in 11 patients; of these, five $(20.8 \%)$ were severe complications (grades $3 \mathrm{~b}$ and 4). There were no deaths in the first 30 days after surgery (Table 2).

Postoperative histopathologic study showed the size of the main injury ranging from 0.1 to 12 $\mathrm{cm}$, number of lymph nodes resected from zero to 32 (mean 13, median 14.5) and residual margins free of disease in all cases.

The mean follow-up was ten months, ranging from one to 56 . Mean overall survival was 39.5 months, and disease-free survival, 30.7, being 32.7 months for patients with CRC and 15.7 for the ones with $A C N$, without statistical significance $(p=0.319)$. Blood transfusion, angiolymphatic invasion and lymph node metastasis did not reach significance with respect to overall or disease-free survival (Figure 1).

Table 3. Location of the primary tumor and the type of surgery performed.

\begin{tabular}{|c|c|c|}
\hline Cases & Primary site & Performed resection \\
\hline 1 & Lower rectum & PPE + posterior colpectomy \\
\hline 2 & Middle rectum & PPE \\
\hline 3 & Anal canal & TPE \\
\hline 4 & Lower rectum & PPE + posterior colpectomy \\
\hline 5 & Lower rectum & TPE + colpectomy + vulvectomy + sacrectomy \\
\hline 6 & Right colon & TPE + right colectomy \\
\hline 7 & Middle rectum & TPE \\
\hline 8 & Anal canal & TPE + VRAM reconstruction \\
\hline 9 & Middle rectum & TPE + posterior colpectomy \\
\hline 10 & Lower rectum & PPE + posterior colpectomy \\
\hline 11 & Sigmoid & PPE + unilateral distal ureterectomy with psoas bladder \\
\hline 12 & Anal canal & PPE + posterior colpectomy + VRAM \\
\hline 13 & Lower rectum & PPE + posterior colpectomy + VRAM \\
\hline 14 & Middle rectum & PPE \\
\hline 15 & Lower rectum & PPE + posterior colpectomy \\
\hline 16 & Middle rectum & PPE + posterior colpectomy + right colectomy \\
\hline 17 & Middle rectum & 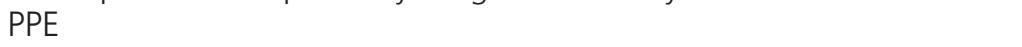 \\
\hline 18 & Sigmoid & PPE \\
\hline 19 & Lower rectum & TPE + left nephrectomy \\
\hline 20 & Lower rectum + colon & PPE + total colpectomy + sacrococcygeal resection + total colectomy \\
\hline 21 & Anal canal & PPE + posterior colpectomy + VRAM and neovagina \\
\hline 22 & Anal canal & PPE + posterior colpectomy + VRAM and neovagina \\
\hline 23 & Middle rectum & TPE + sacrococcygeal resection + VRAM \\
\hline 24 & Anal canal & PPE + posterior colpectomy + VRAM \\
\hline
\end{tabular}

Source: HHJ-ICC (2008-2012).

TPE- Total pelvic exenteration; PPE- posterior pelvic exenteration; VRAM- vertical myocutaneous flap of the rectus abdominis 


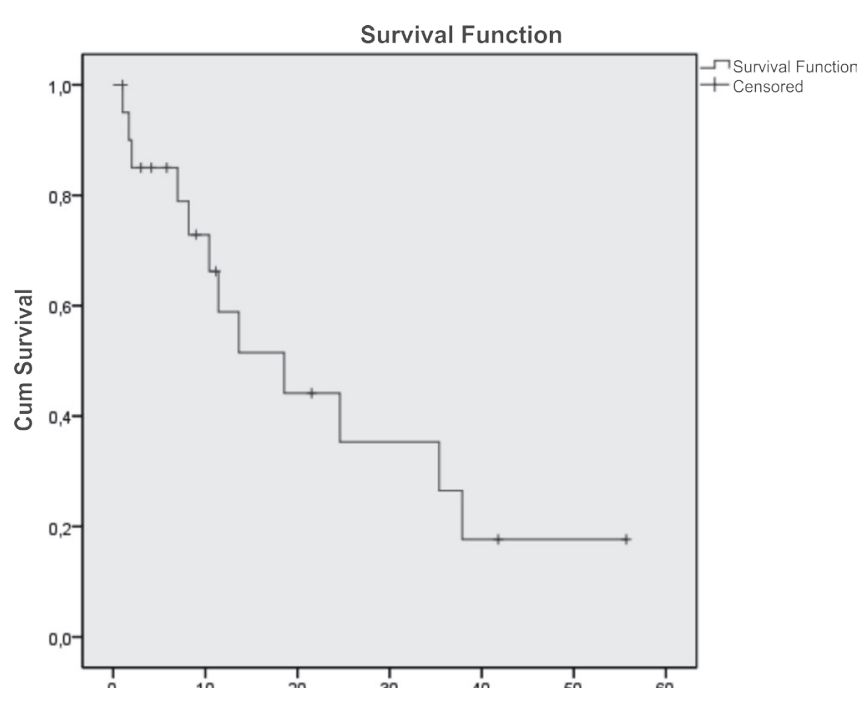

Figura 1. Curva de sobrevida calculada pelo método de Kaplan-Meier.

In the analysis of morbidity clinicopathological factors, we ovserved concomitant cystectomy (TPE) as the only factor that reached statistical significance for the presence of major complications, with a complication rate of $87.5 \%$ ( $p=0.009$, OR 19.5 [95\% Cl 1.7-209.5]). Age greater than 63 years ( $p=0.659)$, intraoperative transfusion $(p=0.278)$ and weight loss greater than $10 \%$ in six months ( $p=0.197)$ did not reach statistical significance as to overall morbidity (Table 4).

\section{DISCUSSION}

Large pelvic resections may represent the only possible cure treatment for advanced colorectal cancer, as well as for selected ACN cases. In general, surgery is the en bloc removal of the rectosigmoid together with the compromised adjacent organs, most commonly the genito-urinary tract (uterus and appendages, bladder and prostate) but often even more complex resections are required, such as colpectomy, vulvectomy or sacrectomy.

The first series of enlarged pelvic resections were published in the mid-twentieth century and focused specifically on PE. At the time, they displayed very high mortality, ranging from 14 to $26.9 \%$ in patients undergoing TPE for primary CRC7,8.

In recent years, however, there was a drastic reduction in surgical mortality, and today this ranges from $0-10 \%$ in specialized centers 9,10 . Among the main factors that contributed to the improvement in surgical mortality, we highlight the better patients selection, the adequacy of the urinary reconstruction technique and the better perioperative care.

Despite the marked improvement in mortality over the years, depending on the radicality required in the enlarged pelvic resections, these can also become mutilating procedures, carrying a high average morbidity rate of 30 to $60 \%$, with a possible decrease in patients' quality of life 11.

Nonetheless, when considering other types of treatment for advanced or recurrent anorectal tumors, the results are even more disappointing, with palliative radiotherapy associated with a median survival of 14 months and an average pain control time of only three months for CRC4. PE, on its turn, as a treatment for such cases, exhibits excellent symptomatic control, and five-year OS ranging from 10 to $30 \% 11,12$. Reported results from the Memorial Sloan-Kettering Cancer Center (MSKCC) in patients undergoing TPE for CRC showed specific cancer survival of 49 months, with a $40 \%$ survival at five years, ranging from $77 \%$ for locally advanced primary CRC cases and $28 \%$ for relapses 13,14 .

In this study, the median overall survival was 39.5 months, similar to that reported by another Brazilian study12, of 37.7 months, although we can not make a direct comparison, since six $(25 \%)$ of this study's cases are primary of the anal canal. Still, the benefit of extended pelvic resection is evident in the locoregional treatment of locally advanced or recurrent anorectal cancer, especially when compared to other treatment modalities.

In this study, six (25\%) patients had relapsed ACN, a higher frequency than that reported in other national series, in which the rescue extended surgery was indicated due to ACN recurrence in only $4.3 \%$ of cases 15 .

The age range was similar to other previous publications, national and international, with medians ranging from 52 to 57.1 years $9,12,13$. The mean age of 60 years is a constant in various reported series, which can be explained by the clear selection of patients with better performance status to undergo a procedure of this magnitude, enhanced by high- 
Table 4. Morbidity factors associated with pelvic exenteration

\begin{tabular}{|c|c|c|c|c|}
\hline \multirow[t]{2}{*}{ Clinicopathological factor } & \multirow[t]{2}{*}{ N } & \multirow{2}{*}{$\begin{array}{l}\text { Absence or mild complications } \\
N(\%)\end{array}$} & \multicolumn{2}{|c|}{ Severe complications } \\
\hline & & & $\mathrm{N}(\%)$ & Valor $p$ \\
\hline \multicolumn{5}{|l|}{ Age $^{*}$} \\
\hline$<63$ years & 17 & $10(58.8 \%)$ & $7(41.2 \%)$ & 0.659 \\
\hline$\geq 63$ years & 7 & $3(42.9 \%)$ & $4(57.1 \%)$ & \\
\hline \multicolumn{5}{|l|}{ Intraoperative transfusion } \\
\hline Yes & 8 & $3(37.5 \%)$ & $5(62.5 \%)$ & 0.278 \\
\hline No & 15 & $9(60 \%)$ & $6(40 \%)$ & \\
\hline \multicolumn{5}{|l|}{ Weight loss >10\% } \\
\hline Yes & 14 & $6(42.9 \%)$ & $8(57.1 \%)$ & 0.197 \\
\hline No & 9 & $7(77.8 \%)$ & $2(22.2 \%)$ & \\
\hline \multicolumn{5}{|l|}{ Total exenteration } \\
\hline Yes & 8 & $1(12.5 \%)$ & $7(87.5 \%)$ & 0.009 \\
\hline No & 15 & $11(73.3 \%)$ & $4(26.7 \%)$ & \\
\hline \multicolumn{5}{|l|}{ Primary Tumor } \\
\hline Anal canal & 6 & $3(50 \%)$ & $3(50 \%)$ & 0.59 \\
\hline Colorectal & 18 & $10(55.6 \%)$ & $8(44.4 \%)$ & \\
\hline
\end{tabular}

Source: HHJ-ICC (2008-2012).

* we used the cutoff age of 63 years to match the 75th percentile of the sample.

er surgical mortality observed in elderly patients as depicted in some older studies7. Being a major surgery, often leaving important consequences for life, such as colostomy or definite urostomy and urinary incontinence, there is always a selection bias of patients who will be submitted to this procedure, the procedure's risk-benefit and life expectancy being weighed, and the age often continuing as a limiting factor.

Regarding nutritional status, we obtained anthropometric data from medical records of 14 patients, of whom $50 \%$ were eutrophic. Two patients (14.2\%) had malnutrition, while other four $(28.5 \%)$ were characterized as overweight or obese by the BMI.

Although the proportion of patients with malnutrition according to the World Health Organization classification16 is small in this study, it is important to highlight the fact that in 14 (58.3\%) cases there was weight loss higher than $10 \%$ in six months, which, as Waitzberg17, is indicative of severe malnutrition, increasing the incidence of fistulae and decreased cellular immunity function, with greater susceptibility to infectious complications. In this work, there were $57.1 \%$ of complications in the group with weight loss versus $22.2 \%$ in patients who did not have significant weight change, although this did not reach statistical significance $(p=0.197)$, possibly due to the small sample size .

All patients were symptomatic, with objective complaints such as chronic pain, severe bleeding and fistula, the time between the symptoms and the first visit to the reference service varying from two to 120 months, with a median of six months. Costa et al. showed similar results, with a total of 15 (100\%) symptomatic patients, seven of whom have two or more symptoms18. Two of our patients had fistulas (rectovaginal or rectovesical). Both were female and had communication of the fistula path to the buttocks skin. In both cases, as also reported by Costa et al.18, the operation solved the symptoms of pain, bleeding, and fistula, with a clear improvement in quality of life (Figure 2).

As for the technical aspects, it is important to note that although Brunschwig5 has described and detailed TPE, radical pelvic resections can never be consid- 


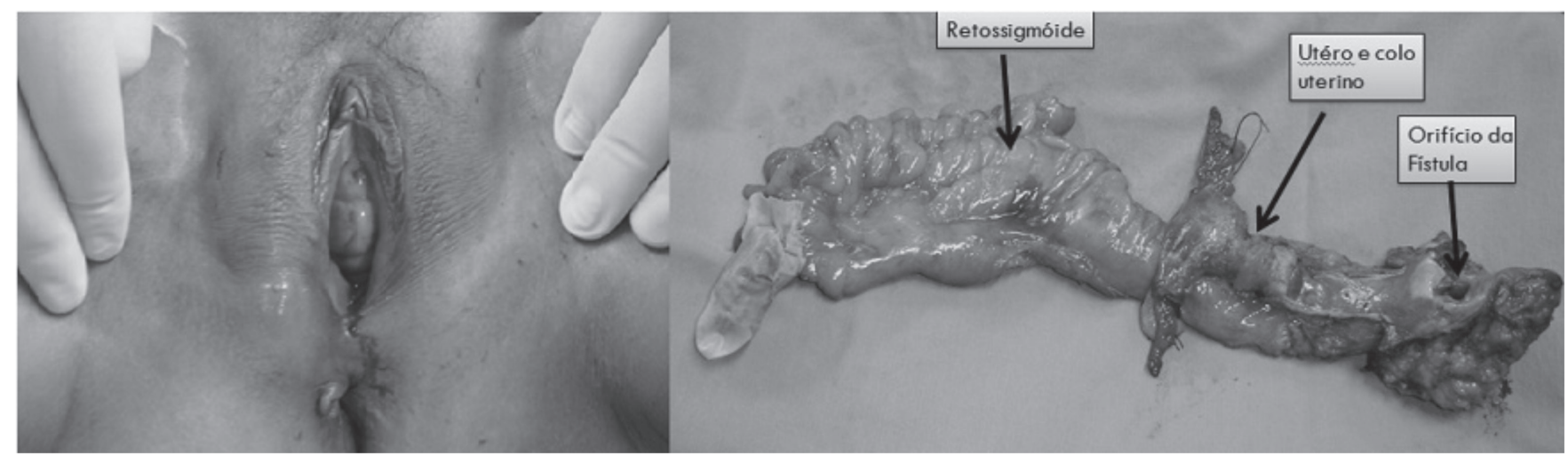

Figure 2 - Rectovaginal fistula. B) Specimen with fistula orifice.

ered fully standardized surgeries, since wider resections may be required to achieve absence of residual disease, including dissections ouside the conventional anatomical planes, with, for example, ureterectomy with bladder flap, sacrectomy, vulvectomy, etc. (Figure 3).

In this work, we carried out 16 PPEs and eight TPEs. Furthermore, additional resection was required in 12 patients, as described in Table 3. Importantly, in seven $(29.1 \%$ ) cases there was need of a myocutaneous flap rotation with perineal reconstruction, a well-established technique for the synthesis of large perineal defects and filling of the pelvic hollow. In two patients, reconstruction with VRAM flap provided the maintenance of sexual ability through the making of a neovagina. All procedures were performed in the same surgical time by a single team.

Even with all perioperative quality evolution, in this study the overall morbidity resulting from necessary resections and reconstructions still persist-

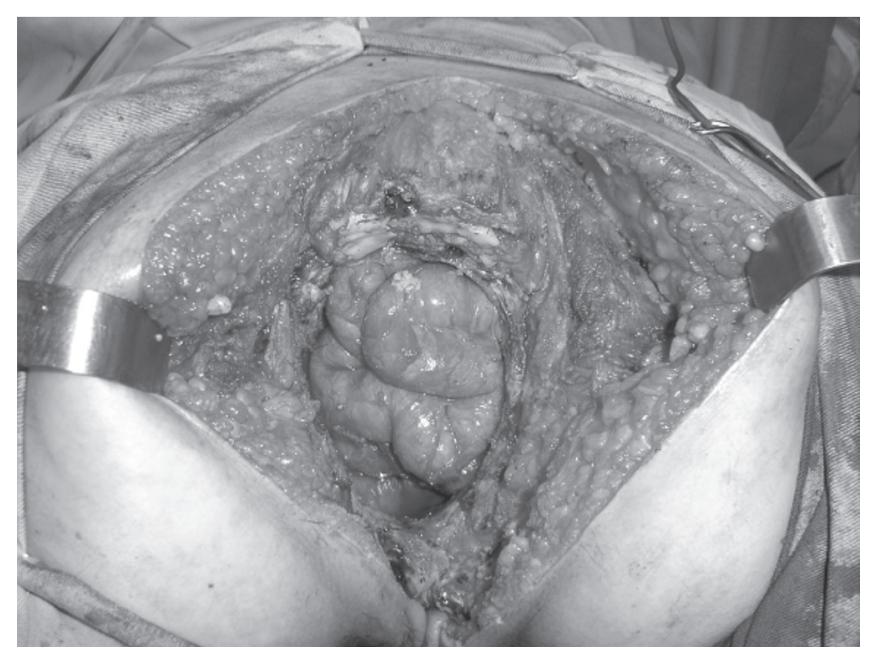

Figure 3 - Surgical field after total pelvic exenteration with sacrectomy (posterior view) ed at a level of $45.8 \%$. In univariate analysis, the only factor that showed significance for the increase in complications was the realization of total pelvic exenteration, with a complication rate of $87.5 \%$ ( $p=$ 0.012). Similar results were previously described19, with $76.9 \%$ morbidity related to radical cystectomy in patients with irradiated pelvis.

The morbidity difference between TPE and PPE found in this study is a well-established fact, the PPE morbidity being close to one of classical rectosigmoidectomy. Lohsiriwat et al. compared a group of patients treated with PPE with patients undergoing rectosigmoidectomy or rectal abdominoperineal resection20. There was no difference between the number of complications and hospital length of stay, the operative time ( 274 vs. $157 \mathrm{~min}, \mathrm{p}<0.001$ ) and blood loss (769 vs. 203, $p=0.008$ ) being higher for PPE. Thus, it is evident that there is a clear difference in surgical morbidity when adding resection of urinary tract.

Regarding follow-up, 13 patients were free of disease at the last follow-up visit, and nine had recurrence diagnosis (including deaths by relapse). In the literature, the main determinants of survival are the presence of lymph node metastasis and angiolymphatic invasion. Although there is a difference in survival dependent on these factors, there was no statistical significance, possibly due to the limiting sample and short follow-up time.

In conclusion, surgical treatment of locally advanced or recurrent colorectal cancer and anal canal is a complex surgical procedure, which has on average $50 \%$ morbidity, reaching levels higher than $80 \%$ when adding the resection of the urinary tract 
in an already irradiated pelvis. The evolution of the surgical technique and the quality of perioperative care associated with a careful selection of patients have been able to reduce surgical mortality to values lower than $5 \%$ in specialized centers. Still, such procedures can present very high morbidity, especially when associated with concomitant cystectomy, which greatly affects the profile of complications.
Candidates for surgery should be evaluated with a careful selection, since additional resections are often necessary, followed by complex reconstruction procedures. Although there are few national publications on the subject, it is important to note that reported Brazilian series have satisfactory results, making extended pelvic resections feasible procedures in large specialized centers.

\title{
R E S U M O
}

\begin{abstract}
Objetivos: avaliar o perfil de morbimortalidade e seus fatores preditivos relacionados às ressecções pélvicas extensas, incluindo a exenteração pélvica, com o intuito de otimizar a seleção dos pacientes e obtenção de melhores resultados cirúrgicos. Métodos: foram realizadas 24 grandes ressecções pélvicas por neoplasia maligna anorretal de 2008 a 2015 no Instituto do Câncer do Ceará. Os fatores analisados incluíram idade, perda de peso, órgão ressecados, exenteração total versus posterior, invasão angiolinfática e perineural, metástase linfonodal e sobrevida global e livre de doença. Resultados: a mediana de idade foi 57 anos e o tempo médio de seguimento foi dez meses. A morbidade global foi 45,8\%, com cinco (20,8\%) complicações graves. Não houve óbito nos primeiros 30 dias de pós-operatório. A sobrevida global média foi 39, 5 meses e a sobrevida livre de doença foi 30,7 meses. A ressecção concomitante da bexiga foi fator prognóstico isolado com maior risco para complicações (87,5\% vs. 26,7\%, p=0.009). Invasão angiolinfática e metástase linfonodal não alcançaram significância com relação à sobrevida livre de doença. Conclusão: o tratamento dos tumores anorretais avançados é desafiador, necessitando frequentemente de ressecções combinadas, como a cistectomia e sacrectomia, além de reconstruções complexas. A magnitude da cirurgia ainda carrega uma elevada taxa de morbidade, porém é um procedimento considerado seguro e factível, com uma baixa mortalidade e adequado controle locorregional tumoral quando realizado em centros de referência.
\end{abstract}

Descritores: Neoplasias. Neoplasias Retais. Recidiva. Canal Anal. Exenteração Pélvica.

\section{REFERÊNCIAS}

1. Ferlay J, Shin HR, Bray F, Forman D, Mathers C, Parkin DM. Estimates of worldwide burden of cancer in 2008: GLOBOCAN 2008. Int J Cancer. 2010;127(12):2893-917.

2. NationalComprehensiveCancerNetwork.NCCNGuidelines - anal carcinoma (version 2.2013). [base de dados na internet]. [acesso em 20 dez 2012]. Disponível em http://www.nccn.org/professionals/physician_gls/pdf/ anal.pdf

3. National Comprehensive Cancer Network. NCCN Guidelines - rectal cancer (version 4.2013). [base de dados na internet]. [acesso em 20 dez 2012]. Disponível em http:// www.nccn.org/professionals/physician_gls/pdf/rectal.pdf

4. Wells BJ, Stotland P, Ko MA, Al-Sukhni W, Wunder J, Ferguson $\mathrm{P}$, et al. Results of an aggressive approach to resection of locally recurrent rectal cancer. Ann Surg Oncol. 2006;14(2):390-5.

5. Brunschwig A. Complete excision of pelvic viscera in the male for advanced carcinoma of the sigmoid invading the urinary bladder. Ann Surg. 1949;129(4):499-504.
6. Dindo D, Demartines N, Clavien PA. Classification of surgical complications: a new proposal with evaluation in a cohort of 6336 patients and results of a survey. Ann Surg. 2004;240(2):205-13.

7. Boey J, Wong J, Ong GB. Pelvic exenteration for locally advanced colorectal carcinoma. Ann Surg. 1982;195(4):513-8.

8. Lopez MJ, Standiford SB, Skibba JL. Total pelvic exenteration. A 50-year experience at the Ellis Fischel Cancer Center. Arch Surg. 1994;129(4):390-5; discussion 395-6.

9. Law WL, Chu KW, Choi HK. Total pelvic exenteration for locally advanced rectal cancer. J Am Coll Surg. 2000;190(1):78-83.

10. De Wever I. Pelvic exenteration: surgical aspects and analysis of early and late morbidity in a series of 106 patients. Acta Chir Belg. 2011;111(5):273-81.

11. Kakuda JT, Lamont JP, Chu DZ, Paz IB. The role of pelvic exenteration in the management of recurrent rectal cancer. Am J Surg. 2003;186(6):660-4.

12. Costa SRP, Teixeira ACP, Lupinacci RA. A exenteração pélvica para o câncer de reto: avaliação dos 
fatores prognósticos de sobrevida em 27 pacientes operados. Rev bras colo-proct. 2008;28(1):7-18.

13. Gannon CJ, Zager JS, Chang GJ, Feig BW, Wood CG, Skibber JM, et al. Pelvic exenteration affords safe and durable treatment for locally advanced rectal carcinoma. Ann Surg Oncol. 2007;14(6):1870-7.

14. Jimenez RE, Shoup M, Cohen AM, Paty PB, Guillem J, Wong WD. Contemporary outcomes of total pelvic exenteration in the treatment of colorectal cancer. Dis Colon Rectum. 2003;46(12):1619-25.

15. Poletto $A H$, Lopes $A$, Carvalho AL, Ribeiro EA, Vieira RA, Rossi BM, et al. Pelvic exenteration and sphincter preservation: an analysis of 96 cases. J Surg Oncol. 2004;86(3):122-7.

16. Organização Mundial da Saúde. BMI Database [banco de dados da internet]. Genebra; 2012 [acesso em 20 dez 2012]. Disponível em: www.who.int/bmi/ index.jsp

17. Waitzberg DL. Nutrição oral, enteral e parenteral na prática clínica. 4a ed. São Paulo: Atheneu; 2009. Nutrição em Cirurgia; p.1712-3.
18. Costa SRP, Antunes RCP, Paula RP, Pedroso MA, Farah JFM, Lupinacci RA. A exenteração pélvica no tratamento do câncer de reto estádio T4: experiência de 15 casos operados. Arq Gastroenterol. 2007;44(4):284-8.

19. Eisenberg MS, Dorin RP, Bartsch G, Cai J, Miranda G, Skinner EC. Early complications of cystectomy after high dose pelvic radiation. J Urol. 2010;184(6):2264-9.

20. Lohsiriwat V, Lohsiriwat D. Comparison of immediate surgical outcomes between posterior pelvic exenteration and standard resection for primary rectal cancer: a matched case-control study. World J Gastroenterol. 2008;14(15):2414-7.

Recebido em: 30/09/2015

Aceito para publicação em: 07/03/2016

Conflito de interesse: nenhum.

Fonte de financiamento: nenhuma.

Endereço para correspondência:

José Wilson Benevides de Mesquita Neto

E-Mail: wilsonmesquita@outlook.com 